\title{
Endovascular Techniques for Dialysis Vascular Access
}

\author{
Vandana Niyyar $^{1}$ and Tushar J. Vachharajani ${ }^{*}, 2$ \\ ${ }^{I}$ Emory University, Atlanta, GA, USA \\ ${ }^{2}$ W.G. (Bill) Hefner Veterans Affairs Medical Center, Salisbury, NC, USA
}

\begin{abstract}
A nephrologist is well equipped to understand and manage the complexities involved in educating and preparing a patient with chronic kidney disease to embrace the challenges involved with renal replacement therapy. The importance of vascular access in providing adequate dialysis therapy cannot be overemphasized. Unfortunately, it remains a weak link in providing optimal care and a major cause of morbidity and mortality. The timely diagnosis of a dysfunctional vascular access involves implementing a good monitoring and surveillance program. A nephrologist of the millennium needs to be well equipped with skills to perform procedures such as fistulogram, percutaenous angioplasty, endovascular thrombectomy and occasionally placement of stents and coils for timely intervention of a dysfunctional access. The current review describes the basic procedures that can be easily performed by nephrologists to provide ideal care to dialysis patients.
\end{abstract}

Keywords: Interventional nephrology, dialysis access, endovascular procedures, angioplasty, angiography, vascular access, Thrombectomy.

\section{INTRODUCTION}

Vascular access dysfunction is a major cause of morbidity and mortality in dialysis patients [1]. With their unique perspective on dialysis patients and their problems, an increasing number of nephrologists are safely and effectively performing endovascular procedures to assist in the maintenance of hemodialysis accesses [2]. This article aims to describe the basic vascular access related procedures performed by interventional nephrologists such as angiography, angioplasty and endovascular thrombectomy.

\section{ANGIOGRAPHY}

A diagnostic angiogram is usually performed to evaluate a graft or a fistula in its entirety, with the purpose of identifying any stenotic lesions within the dialysis access. It must be kept in mind that the dialysis access is a circuit, which begins and ends in the heart [3] and the angiogram should include, at a bare minimum: the feeding artery and the anastomosis, the juxta-anastomosis, the body of the access, the venous outflow and the central veins. If a therapeutic intervention is indicated, an angioplasty is performed in combination with the angiogram.

\section{DESCRIPTION OF AN ANGIOGRAM}

To obtain initial venous access, the access is cannulated using an 18 gauge (for arterio-venous graft; $\mathrm{AVG}$ ) or a 21 gauge (for arterio-venous fistula; AVF) thin-walled needle. A guidewire is then passed into the access, and the needle is exchanged for a vascular sheath, which is used to inject radiocontrast for imaging of the access. If the cannulation is in the downstream direction, a retrograde occlusive arteriogram is performed to evaluate the artery and the juxta-

*Address correspondence to this author at the 1601 Brenner Avenue, Salisbury, NC 28144, USA; Tel: 704-638-9000; Fax: 704-638-3855;

E-mail: Tushar.vachharajani@va.gov anastomotic region. Alternatively, and sometimes preferentially [4], the access may be cannulated in the antegrade direction and the arterial system is evaluated by direct visualization, with selective cannulation of the artery.

\section{ANGIOPLASTY}

Significant vascular access stenosis identified on an angiogram may be treated by percutaneous transluminal angioplasty (PTA). Stenoses are most common at the venous anastomotic site in an AVG, though they may occur both peripherally throughout the access including the arterial, juxta-anastomotic and intra-graft areas, as well as within the central venous system [5]. Neo-intimal hyperplasia at the graft-vein interface is believed to be a major factor in the underlying pathophysiology of venous access stenosis [6].

Percutaneous balloon angioplasty should be performed only in cases with functionally significant stenosis, as defined as a decrease of greater than $50 \%$ of normal vessel diameter, accompanied by hemodynamic or clinical abnormality, such as abnormal recirculation values, elevated venous pressures, decreased blood flow, swollen extremity, unexplained reduction in $\mathrm{Kt} / \mathrm{V}$, or elevated negative arterial prepump pressures, that prevent achieving the prescribed blood flow $[7,8]$.

It should be noted that an angioplasty is not a benign procedure and can cause substantial trauma to the vascular endothelium. The vascular injury may heal without any significant sequelae, or it may incite the development of a new stenosis or accelerate the progression of a preexisting subclinical lesion $[6,9,10]$.

Success is defined as less than $30 \%$ residual stenosis post-procedure and resolution of physical indicators of stenosis and 50\% unassisted patency at 6 months. Though PTA is safe, effective, and can be easily performed in an outpatient setting with minimal discomfort to the patient, 
there are still unanswered questions regarding its long-term efficacy and whether it truly is an effective intervention for vascular access dysfunction [9].

\section{DESCRIPTION OF AN ANGIOPLASTY}

After cannulating the access, an initial angiogram is performed to identify any stenotic lesions within the access. A guidewire is then introduced through the vascular sheath and passed across the stenotic lesion. An angioplasty balloon catheter of appropriate size is then advanced over the guidewire to the identified stenotic lesions or the venous anastomosis at the graft-vein interface. The angioplasty balloon is inflated with dilute radiocontrast so that it may be visualized by using fluoroscopy, until there is full balloon effacement. (Figs. 1, 2). In general, an angioplasty balloon catheter is over-sized about $20 \%$ for a venous angioplasty. A residual stenosis of $30 \%$ or less is commonly used as the definition of success for all angioplasty procedures.

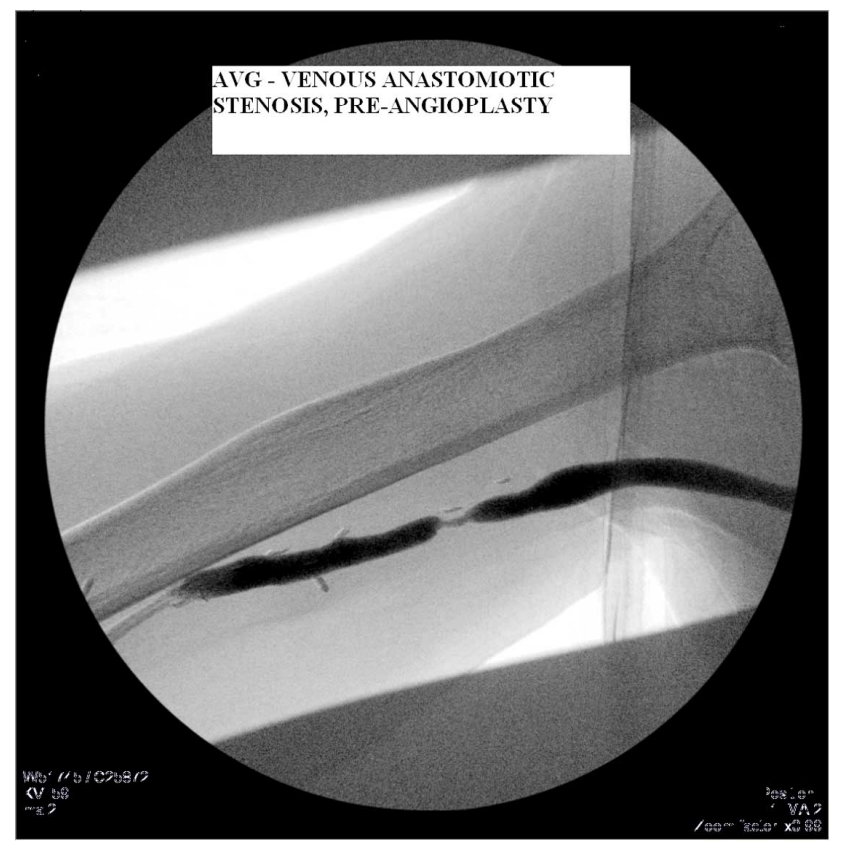

Fig. (1). Arteriovenous graft: venous anastomosis stenosis, prior to angioplasty.

\section{OUTCOMES}

K-DOQI recommends a minimum $50 \%$ unassisted patency at 6 months with PTA and a 50\% 1-year unassisted patency after surgical revision. Surgical revision is held to a higher standard, as it usually extends the access farther up the extremity by the use of a jump graft and thus has the potential for loss of venous 'real-estate'. Most studies in the past have shown patency with endovascular techniques at least as good if not better, as detailed in Table 1. Studies that have directly compared PTA versus surgical revision for venous stenoses show conflicting results $[11,12]$.

\section{ENDOVASCULAR THROMBECTOMY:}

Eighty-five to ninety percent of arteriovenous access thromboses are associated with venous outflow stenotic lesions $[13,14]$ caused by endothelial and fibromuscular hyperplasia. Thrombectomy procedures are routinely performed by nephrologists, using a combination of mechanical and pharmaco-mechanical techniques. Stenoses accompanied by thromboses are more difficult to treat than stenoses detected by prospective monitoring; treatment of stenoses associated with thrombosis is therefore associated with poorer outcomes for both surgical and percutaneous techniques. Endovascular techniques yield 3-month patencies ranging from $30 \%$ to $40 \%[15,16]$. K-DOQI recommends a minimum of $85 \%$ immediate patency for both percutaneous thrombolysis and surgically revised thrombectomies; $40 \%$ unassisted patency and functionality at 3 months for endovascular procedures, and 50\% unassisted patency and functionality at 3 months for surgical procedures $[17,18]$. As in angioplasty, surgical revision is held to a higher standard. Thrombosed arteriovenous fistulas were previously believed to be unsalvageable. Although the procedures are technically more challenging in fistulas, results are similar to graft interventions.

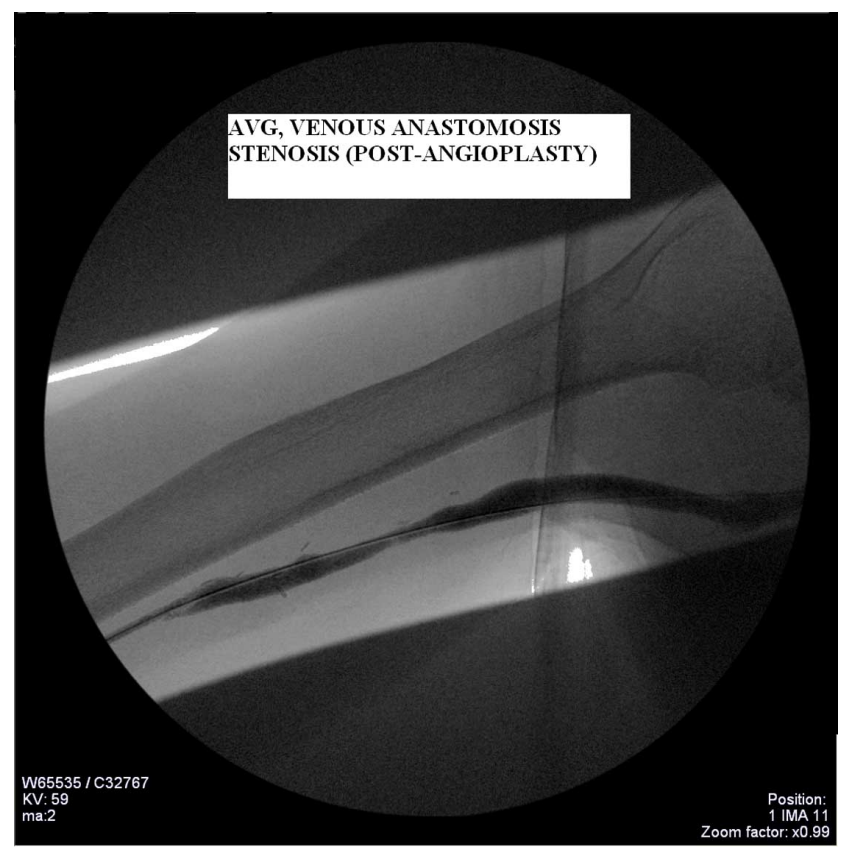

Fig. (2). Arteriovenous graft: venous anastomosis stenosis, postangioplasty, with minimal residual stenosis

\section{DESCRIPTION OF A THROMBECTOMY [19]}

In accomplishing successful thrombectomy of a vascular access, 4 steps are required:

1. Diagnostic angiogram to evaluate the graft or fistula, along with the venous outflow and central veins

2. Removal of the thrombus from the vascular access

3. Treatment of stenosis by using angioplasty

4. Dislodgement of the arterial plug to reestablish flow

Although the order in which these 4 steps are performed is physician and patient dependent, all 4 steps must be performed for successful restoration of blood flow through the vascular access.

Endovascular thrombectomy is performed most commonly by using thromboaspiration, which combines angiography, thrombectomy by means of thrombus aspiration, and balloon angioplasty. This procedure requires 
Table 1. Patency Rates with PTA in Dialysis Access

\begin{tabular}{|c|c|c|c|c|c|}
\hline Investigator & Year & Immediate Patency & 3-Month Patency & 6-Month Patency & 1-Year Patency \\
\hline \hline Beathard [5] & 1992 & $94 \%$ & $77.2 \%$ & $66.4 \%$ & $44.5 \%$ \\
\hline Kanterman [23] & 1995 & Not reported & Not reported & $63 \%$ & $41 \%$ \\
\hline Glanz [24] & 1987 & $82 \%$ & Not reported & Not reported & $45 \%$ \\
\hline Mori [25] & 1994 & Not reported & $68 \%$ & $42 \%$ & $25 \%$ \\
\hline Turmel-Rodrigues L [26] & 1993 & $95 \%$ & Not reported & Not reported & $82 \%$ \\
\hline
\end{tabular}

accessing the vascular access through a vascular sheath, then selecting a guidewire and embolectomy catheter. Accessing the thrombosed vascular access often is the most difficult part of the thrombectomy procedure because usually there is no blood 'flashback' into the cannulation needle. Both the venous and arterial sides of the thrombosed access must be cannulated. It is preferable to first cannulate a straight section for insertion of the balloon catheter on the venous side of the access. The sites for cannulation should be chosen to ensure that there is enough space between the 2 vascular access sites to allow for sweeping the thrombus from the vascular lumen.

To obtain initial venous access, a graft is cannulated using an 18-G thin-walled needle in the downstream direction. A guidewire then is passed into the access, and the needle is exchanged for a 6- or 7-Fr vascular sheath. In the case of an autogenous fistula, a 21-G micropuncture needle is used first to gain access to the fistula. Ultrasound guidance may be required for cannulation. The vascular sheath facilitates aspiration of the thrombus, allows for easy introduction of the angioplasty balloon catheter or embolectomy catheter, and is used to inject radiocontrast for imaging of the access.

The guidewire then is passed up to the level of the central veins, and a straight catheter is advanced over the guidewire to the central veins to obtain a central venous angiogram. After the central venous angiogram is obtained, any necessary drugs may be administered through this catheter, including heparin and medications used for conscious sedation.

The straight catheter is pulled back toward the introduction site to obtain an angiogram of the peripheral veins. Contrast is injected while the catheter is pulled back to delineate and identify stenotic lesions with or without thrombi.

An angioplasty balloon catheter of appropriate size is then advanced over the guidewire to the identified stenotic lesions or the venous anastomosis at the graft-vein interface. The angioplasty balloon is inflated with dilute radiocontrast so that it may be visualized by using fluoroscopy, until there is complete balloon effacement. The entire venous side of the graft then is sequentially dilated. The angioplasty balloon is removed, leaving the wire in place to maintain access to the central circulation.

The graft is now cannulated with the needle pointed upstream toward the arterial anastomosis at a point approximately $4 \mathrm{~cm}$ from the venous anastomosis. A guidewire is advanced into the access through the needle, and the needle is exchanged for another vascular sheath. A 4Fr embolectomy catheter is advanced arterially through the vascular sheath. Under fluoroscopic guidance, the embolectomy catheter is pulled across the arterial anastomosis while aspirating the thrombus through the sheath side port. It may be necessary to repeat this action several times until flow is restored, indicated by a good pulse in the graft. Flow can be confirmed by injecting a small amount of radiocontrast through the side port of the venous directed sheath. If there is rapid disappearance of the contrast, a digital subtraction angiogram is obtained.

At this point, the interventionist must determine whether there is either an inflow or outflow stenosis that will require additional angioplasty. If there is evidence of an inflow stenosis, an arterial angiogram may be indicated, in which case a guidewire is advanced into the artery. A vascular catheter then is advanced over the wire, and radiocontrast is injected to visualize the artery, arterial anastomosis, and juxta-anastomotic segment. Upon recognition of an arterial stenosis, an appropriate-sized angioplasty balloon is advanced over the guidewire and inflated. In similar fashion, if a stenosis is present in the juxta-anastomotic segment, dilation using the appropriate-sized angioplasty balloon catheter is performed. In general, an angioplasty balloon catheter is oversized by about $20 \%$ for venous angioplasty and the balloon is sized according to the arterial diameter for arterial angioplasty, though there are no controlled studies that have examined angioplasty balloon sizing on clinical outcomes. A comparison of ultra-high pressure balloons versus high-pressure balloons for venous anastomosis stenosis in arterio-venous grafts showed no significant improvement in patency on routine angioplasties [20]. Another study that evaluated the effect of prolonged inflation times (1 minute versus 3 minutes) found that although a 3 minute inflation time significantly improved the likelihood of technical success, there was no significant difference in postintervention access patency [21].

A repeat angiogram is obtained to evaluate results of the angioplasty and identify any complications. When satisfied that the procedure is complete, hemostasis is obtained by removing the vascular sheaths and applying manual pressure over the puncture sites. A suture may be used to temporarily close the puncture sites. The procedure is considered successful if unobstructed flow through the access is established to allow for one subsequent dialysis treatment.

\section{OUTCOMES}

Both endovascular and surgical techniques may be used to perform thrombectomies. The KDOQI guidelines indicate 
Table 2. Comparison of Different Techniques for Thrombosed Access

\begin{tabular}{|l|l|l|}
\hline \multicolumn{1}{|c|}{ Investigator } & Year & \multicolumn{1}{c|}{ Results } \\
\hline \hline Beathard [27] & 1995 & Equivalent overall, though long-term patency of endovascular techniques was superior \\
\hline Schuman [28] & 1994 & Surgical thrombectomy superior \\
\hline Schwartz [18] & 1995 & Equivalent overall, though shorter hospital stay and lower anesthesia requirements noted with endovascular techniques \\
\hline Tordoir [29] (meta-analysis) & 2009 & Equivalent overall in grafts, though surgery may be preferred in autogenous fistulae \\
\hline Uflacker [30] & 1999 & Equivalent overall, no statistically significant differences in primary or secondary patency \\
\hline Vesely [31] & 1999 & Surgical significantly better in long-term patency, though results of both inferior to published guidelines \\
\hline Marston [32] & 1997 & Surgical significantly better in long-term patency \\
\hline Dougherty [33] & 1999 & Equivalent overall, no statistically significant differences in primary or secondary patency \\
\hline Green [34] (meta-analysis) & 2002 & Surgical approach superior \\
\hline
\end{tabular}

that percutaneous transluminal angioplasty of a thrombosed vascular access should result in $40 \%$ patency at 3 months $[15,16]$, with immediate patency of $85 \%$, whereas the recommendation for surgical thrombectomy is $50 \%$ unassisted patency and functionality at 3 months $[17,18]$. However, there are few randomized studies comparing the two procedures directly. Table 2 summarizes the results of some of those. It should be kept in mind that the older studies show better surgical outcomes, but with the improvement and standardization in endovascular techniques, the outcomes for both endovascular and surgical techniques are comparable.

\section{COMPLICATIONS}

A procedure related complication is defined as an unexpected adverse event that requires additional therapy. The American Society of Diagnostic and Interventional Nephrology (ASDIN- www.asdin.org) has recently released a Position Statement classifying complications associated with hemodialysis vascular access procedures. In this system, the "type" of complication refers to the procedure being performed or the involved vessel and the "grade" refers to the intensity of the medical care required to address the complication. 10 types and 4 grades of complications have been described in detail. Among these, those related to the endovascular techniques described above include access site hematoma, vascular rupture, arterial complications, medication reactions and systemic complications.

\section{CONCLUSIONS}

A major pre-requisite for adequate hemodialysis treatment in end-stage renal disease patients is a functioning vascular access. Endovascular therapy is an important addition to the interventionist's armamentarium and helps in maintaining and prolonging the longevity of each access [22]. Percutaneous procedures are safe and effective, and can be performed in an outpatient setting with minimal discomfort to the patient.

\section{ACKNOWLEDGEMENT}

Declared none.

\section{CONFLICT OF INTEREST}

Declared none.

\section{REFERENCES}

[1] Romer M, Dougherty N, Amores-Lafleur E. Predoctoral education in special care dentistry: paving the way to better access? ASDC J Dent Child 1999; 66: 132-5, 85.

[2] Beathard GA, Litchfield T. Effectiveness and safety of dialysis vascular access procedures performed by interventional nephrologists. Kidney Int 2004; 66: 1622-32.

[3] Asif A, Gadalean FN, Merrill D, et al. Inflow stenosis in arteriovenous fistulas and grafts: a multicenter, prospective study. Kidney Int 2005; 67: 1986-92.

[4] Yevzlin AS. On the retrograde occlusive arteriogram. Semin Dial 2009; 22: 702-3.

[5] Beathard GA. Percutaneous transvenous angioplasty in the treatment of vascular access stenosis. Kidney Int 1992; 42: 1390-7.

[6] Roy-Chaudhury P, Sukhatme VP, Cheung AK. Hemodialysis vascular access dysfunction: a cellular and molecular viewpoint. J Am Soc Nephrol 2006; 17: 1112-27.

[7] Vascular Acess Work Group. Clinical practice guidelines for vascular access. Am J Kidney Dis 2006; 48: S248-73.

[8] Vascular Acess Work Group. Clinical practice guidelines for vascular access. Am J Kidney Dis 2006; 48: S176-247.

[9] White JJ, Bander SJ, Schwab SJ, et al. Is percutaneous transluminal angioplasty an effective intervention for arteriovenous graft stenosis? Semin Dial 2005; 18: 190-202.

[10] Chang CJ, Ko PJ, Hsu LA, et al. Highly increased cell proliferation activity in the restenotic hemodialysis vascular access after percutaneous transluminal angioplasty: implication in prevention of restenosis. Am J Kidney Dis 2004; 43: 74-84.

[11] Brooks JL, Sigley RD, May KJ, Jr., Mack RM. Transluminal angioplasty versus surgical repair for stenosis of hemodialysis grafts. A randomized study. Am J Surg 1987; 153: 530-1.

[12] Dapunt O, Feurstein M, Rendl KH, Prenner K. Transluminal angioplasty versus conventional operation in the treatment of haemodialysis fistula stenosis: results from a 5 -year study. $\mathrm{Br} \mathrm{J}$ Surg 1987; 74: 1004-5.

[13] Palder SB, Kirkman RL, Whittemore AD, Hakim RM, Lazarus JM, Tilney NL. Vascular access for hemodialysis. Patency rates and results of revision. Ann Surg 1985; 202: 235-9.

[14] Etheredge EE, Haid SD, Maeser MN, Sicard GA, Anderson CB. Salvage operations for malfunctioning polytetrafluoroethylene hemodialysis access grafts. Surgery 1983; 94: 464-70.

[15] Middlebrook MR, Amygdalos MA, Soulen MC, et al. Thrombosed hemodialysis grafts: percutaneous mechanical balloon declotting versus thrombolysis. Radiology 1995; 196: 73-7.

[16] Beathard GA. Mechanical versus pharmacomechanical thrombolysis for the treatment of thrombosed dialysis access grafts. Kidney Int 1994; 45: 1401-6.

[17] Sands JJ, Miranda CL. Prolongation of hemodialysis access survival with elective revision. Clin Nephrol 1995; 44: 329-33.

[18] Schwartz CI, McBrayer CV, Sloan JH, Meneses P, Ennis WJ. Thrombosed dialysis grafts: comparison of treatment with transluminal angioplasty and surgical revision. Radiology 1995; 194: 337-41. 
[19] Niyyar VD, Work J. Interventional nephrology: core curriculum 2009. Am J Kidney Dis 2009; 54: 169-82.

[20] Rajan DK, Platzker T, Lok CE, et al. Ultrahigh-pressure versus high-pressure angioplasty for treatment of venous anastomotic stenosis in hemodialysis grafts: is there a difference in patency? J Vasc Interv Radiol 2007; 18: 709-14.

[21] Forauer AR, Hoffer EK, Homa K. Dialysis access venous stenoses: treatment with balloon angioplasty--1- versus 3-minute inflation times. Radiology 2008; 249: 375-81.

[22] Greenberg JI, Suliman A, Angle N. Endovascular dialysis interventions in the era of DOQI. Ann Vasc Surg 2008; 22: 657-62.

[23] Kanterman RY, Vesely TM, Pilgram TK, Guy BW, Windus DW, Picus D. Dialysis access grafts: anatomic location of venous stenosis and results of angioplasty. Radiology 1995; 195: 135-9.

[24] Glanz S, Gordon DH, Butt KM, Hong J, Lipkowitz GS. The role of percutaneous angioplasty in the management of chronic hemodialysis fistulas. Ann Surg 1987 ; 206: 777-81.

[25] Mori Y, Horikawa K, Sato K, Mimuro N, Toriyama T, Kawahara $\mathrm{H}$. Stenotic lesions in vascular access: treatment with transluminal angioplasty using high-pressure balloons. Intern Med 1994; 33: 284-7.

[26] Turmel-Rodrigues L, Pengloan J, Blanchier D, et al. Insufficient dialysis shunts: improved long-term patency rates with close hemodynamic monitoring, repeated percutaneous balloon angioplasty, and stent placement. Radiology 1993; 187: 273-8.

[27] Beathard GA. Thrombolysis versus surgery for the treatment of thrombosed dialysis access grafts. J Am Soc Nephrol 1995; 6: 1619-24.
[28] Schuman E, Quinn S, Standage B, Gross G. Thrombolysis versus thrombectomy for occluded hemodyalisis grafts. Am J Surg 1994; 167: 473-6.

[29] Tordoir JH, Bode AS, Peppelenbosch N, van der Sande FM, de Haan MW. Surgical or endovascular repair of thrombosed dialysis vascular access: is there any evidence? J Vasc Surg 2009; 50: 9536.

[30] Uflacker R, Rajagopalan PR, Vujic I, Stutley JE. Treatment of thrombosed dialysis access grafts: randomized trial of surgical thrombectomy versus mechanical thrombectomy with the Amplatz device. J Vasc Interv Radiol 1996; 7: 185-92.

[31] Vesely TM, Williams D, Weiss M, et al. Comparison of the angiojet rheolytic catheter to surgical thrombectomy for the treatment of thrombosed hemodialysis grafts. Peripheral AngioJet Clinical Trial. J Vasc Interv Radiol 1999; 10: 1195-205.

[32] Marston WA, Criado E, Jaques PF, Mauro MA, Burnham SJ, Keagy BA. Prospective randomized comparison of surgical versus endovascular management of thrombosed dialysis access grafts. J Vasc Surg 1997; 26: 373-80; discussion 80-1.

[33] Dougherty MJ, Calligaro KD, Schindler N, Raviola CA, Ntoso A. Endovascular versus surgical treatment for thrombosed hemodialysis grafts: A prospective, randomized study. J Vasc Surg 1999; 30: 1016-23.

[34] Green LD, Lee DS, Kucey DS. A metaanalysis comparing surgical thrombectomy, mechanical thrombectomy, and pharmacomechanical thrombolysis for thrombosed dialysis grafts. J Vasc Surg 2002; 36: 939-45.

(C) Niyyar and Vachharajani; Licensee Bentham Open.

This is an open access article licensed under the terms of the Creative Commons Attribution Non-Commercial License (http://creativecommons.org/licenses/by-nc/3.0/) which permits unrestricted, non-commercial use, distribution and reproduction in any medium, provided the work is properly cited. 